\title{
Mitochondrial DNA mutations and essential hypertension (Review)
}

\author{
YU DING ${ }^{1,2}$, BOHOU XIA ${ }^{3}$, JINFANG YU ${ }^{4}$, JIANHANG LENG ${ }^{1,2}$ and JINYU HUANG ${ }^{2,5}$ \\ ${ }^{1}$ Central Laboratory, Hangzhou First People's Hospital; ${ }^{2}$ Affiliated Hangzhou Hospital, \\ Nanjing Medical University, Hangzhou, Zhejiang; ${ }^{3}$ Department of Pharmacy, Hunan University of Chinese Medicine, \\ Changsha, Hunan; ${ }^{4}$ Department of Cardiology, Xiaoshan First People's Hospital; ${ }^{5}$ Department of Cardiology, \\ Hangzhou First People's Hospital, Nanjing Medical University, Hangzhou, Zhejiang, P.R. China
}

Received May 1, 2013; Accepted July 22, 2013

DOI: $10.3892 /$ ijmm.2013.1459

\begin{abstract}
Essential hypertension (EH) is a frequent, chronic, age-related disorder, which remains a major modifiable risk factor for cardiovascular disease despite important advances in our understanding of its pathophysiology. Previous studies have noted a consistent maternal effect on blood pressure (BP). Consequently, mutations in mitochondrial DNA (mtDNA) have become an additional target of investigations on the missing BP heritability. Among these mutations, mt-transfer RNA (tRNA) is a hot mutational spot for pathogenic mutations associated with EH. Mutant mtDNA aggravates mitochondrial dysfunction, pivotally contributing to the clinical phenotype. Moreover, the damaged mitochondria, due to their inability to provide the high-energy requirements for cells, generate reactive oxygen species (ROS) and induce mitochondrial-mediated cell death pathways. Therefore, mitochondrial dysfunction plays a critical role in the pathogenesis of $\mathrm{EH}$. This review summarizes the basic knowledge of mitochondrial genetics and $\mathrm{EH}$-associated mtDNA mutations and further discusses the molecular mechanisms behind these mtDNA mutations in clinical manifestations of EH.
\end{abstract}

\section{Contents}

1. Introduction

2. Mitochondrial genome and mitochondrial genetics

3. Mitochondrial function and dysfunction

4. Oxidative stress and hypertension

5. Role of mtDNA mutations in $\mathrm{EH}$

6. Molecular mechanisms behind mtDNA mutations associated with EH

7. Conclusion

Correspondence to: Dr Jinyu Huang, Department of Cardiology, Hangzhou First People's Hospital, Nanjing Medical University, 261 Huan Sha Road, Hangzhou, Zhejiang 310006, P.R. China E-mail: hjyu41@sohu.com

Key words: mitochondria, mutation, essential hypertension, dysfunction

\section{Introduction}

Hypertension is an established risk factor for coronary heart disease, stroke, congestive heart failure and renal dysfunction. Despite significant advances in our understanding of the pathophysiology of hypertension, it remains to be one of the world's greatest public health issues (1). It is estimated that one third of the world's adult population will be hypertensive by 2025 (2). In particular, in industrialized countries, the risk of becoming hypertensive [blood pressure (BP) $>140 / 90 \mathrm{mmHg}$ ] during a lifetime exceeds $90 \%$ (3). Essential hypertension $(\mathrm{EH})$, or hypertension due to undetermined causes, accounts for $>90 \%$ of cases of hypertension. It is a heterogeneous disorder, with different patients having different causal factors that lead to high BP.

To date, the etiology of $\mathrm{EH}$ is not well understood due to multifactorial causes. It is generally believed that $\mathrm{EH}$ is a multifactorial trait involving interactions among genetic, environmental and demographic factors (4). Of these, hereditary factors account for 30 to $50 \%$ of BP variability (5). Variations in a variety of genes have shown an association with hypertension in certain studies; however, these associations are often not reproducible in studies on other populations. Improved techniques of genetic analysis, particularly genome-wide linkage analysis, have enabled the search for genes that contribute to the development of primary hypertension in the population $(6,7)$. However, the majority of the reported genetic variants were identified in studies of the nuclear genome (8-10); only limited insights have been gained from the investigation of the mitochondrial genome.

This review provides a detailed introduction of the mitochondrial genome, summarizes the results of studies on the role of mitochondrial DNA (mtDNA) mutations associated with EH published thus far, and highlights some of the general conclusions that have become apparent.

\section{Mitochondrial genome and mitochondrial genetics}

Mitochondria are bacterium-sized organelles found in all nucleated cells (11). Uniquely, they contain their own genome (mtDNA) and it is widely accepted that mitochondria originate from aerobic bacteria engulfed by an anaerobic eukaryotic cell. 


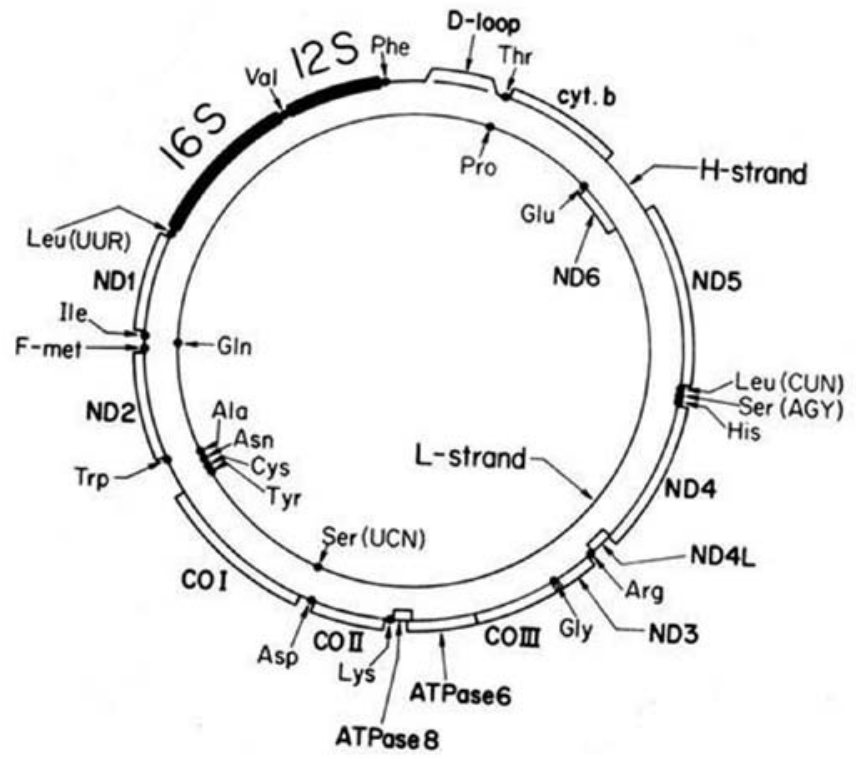

Figure 1. Genetic map of the human mitochondrial genome. The outer circle represents the heavy $(\mathrm{H})$ strand and the inner circle the light $(\mathrm{L})$ strand.

Mammalian mtDNA encodes 13 proteins that are subunits of the oxidative phosphorylation (OXPHOS) system and 22 transfer RNAs (tRNAs) and 2 ribosomal RNAs (rRNAs) (Fig. 1). The mitochondrial OXPHOS complexes are assembled from genes distributed between mtDNA and nuclear DNA (nDNA) (12). Unlike nDNA, mtDNAs are maternally inherited and are present in multiple copies/cell. The numbers vary according to the bioenergentic needs of each unique tissue and can range over three orders of magnitude, depending on the cell type (13).

Each mammalian cell contains hundreds of mitochondria and thousands of mtDNAs. Since mtDNA is in the proximity of reactive oxygen species (ROS) generation sites and mitochondria have less sophisticated DNA protection and repair systems, mtDNA is hence vulnerable to a high mutation rate (14). The most prominent is polyplasmy. Polyplasmy is the basis of heteroplasmy (alternations of mtDNA may be present in some of the mtDNA molecules) and homoplasmy (mutations in all of the molecules). Neutral polymorphisms are usually homoplasmic, whereas pathogenic mutations are usually heteroplasmic in nature, and $\mathrm{EH}$-associated mtDNA mutations are commonly homoplasmic or almost homoplasmic.

\section{Mitochondrial function and dysfunction}

Mitochondria exert both vital and lethal functions in physiological and pathological conditions. On the one hand, they provide the majority of cellular energy in the form of adenosine5'-triphosphate (ATP) through OXPHOS (15). Additionally, they are involved in a variety of processes, including regulation of the cell cycle, cell signaling, apoptosis and calcium $\left(\mathrm{Ca}^{2+}\right)$ buffering $(12,16,17)$.

Oxygen radicals, such as ROS, are also generated during OXPHOS as a toxic byproduct in the mitochondria, which may damage the mitochondrial and cellular DNA, protein, lipids and other molecules, leading to oxidative stress and mitochondrial dysfunction $(18,19)$. An impairment of normal mitochondrial function leads to an excessive production of ROS and a general decrease in ATP levels. Moreover, there is a concomitant loss of mitochondrial transmembrane potential (20). Excessive ROS and $\mathrm{Ca}^{2+}$ production lead to mitochondrial outer membrane permeabilization and to the release into the cytosol of cytotoxic proteins normally confined within the mitochondrial intermembrane space. As a result, this process induces apoptosis or necrosis (21).

\section{Oxidative stress and hypertension}

In animal models, oxidative stress has been observed in spontaneously hypertensive rats (22), renovascular hypertension (23) and salt-sensitive hypertension (24). Although its pathogenesis is complex and multifactorial, human hypertension is considered as a state of increased oxidative stress (25). An excessive endothelial production of ROS and nitric oxide synthase (NOS) may lead to impaired endothelium-dependent vasorelaxation in human internal mammary arteries and the saphenous vein (26), contributing to vascular pathophysiology by promoting increased vascular tone, cell growth, as well as the activation of matrix metalloproteinases and the deposition of extracellular matrix proteins, which are processes associated with the vascular phenotype of hypertension (27).

\section{Role of mtDNA mutations in EH}

$12 S$ rRNA A1555G mutation. The A1555G mutation in the $12 \mathrm{~S}$ rRNA gene has been associated with aminoglycosideinduced and non-syndromic hearing loss in various ethnic populations (28-31). Chen et al (32) described two Han Chinese families with hearing loss and hypertension carrying the homoplasmic A1555G mutation. An A to $G$ transition at this position in the 12S rRNA gene has been predicted to encode an aminoglycoside binding based on sequence similarity to Escherichia coli (33) and alters mitochondrial ribosomal function and translation (34-36), which in turn causes OXPHOS defects that are thought to contribute to the clinical pathology of hypertension. Insufficient metabolism caused by mitochondrial dysfunction may lead to the elevation of systolic BP and may be involved in the development of hypertension (37).

ND1 T3308C mutation. The homoplasmic ND1 T3308C mutation is a known disease-associated mutation. This mutation has been suggested to contribute to the higher penetrance of hearing loss in a large African family than Japanese and French pedigrees carrying the tRNA ${ }^{\mathrm{Ser}(\mathrm{UCN})} \mathrm{T} 7511 \mathrm{C}$ mutation $(38,39)$. Liu et al (40) reported a Han Chinese family carrying the ND1 T3308C mutation with $\mathrm{EH}$. The T to C transition at position 3308 causes translation-initiating methionine with a threonine in ND1. Thus, the ND1 mRNA is shortened by two amino acids (41). Moreover, the T3308C mutation is also located in two nucleotides adjacent to the $3^{\prime}$ end of the tRNA $^{\text {Leu(UUR) }}$ gene; the T3308C mutation also affects the processing of the H-strand polycistronic RNA precursors (42).

ND5 T12338C mutation. The well-known T12338C mutation in the ND5 gene, combined with tRNA ${ }^{\text {Leu(CUN) }}$ A12330G mutation, has been found in a three generation Han Chinese 
family with high penetrance of $\mathrm{EH}$ (43). Moreover, this mutation was also shown to be present in a Chinese family with hypertrophic cardiomyopathy (44). In fact, the ND5 T12338C mutation, which is similar to the ND1 T3308C mutation, causes a replacement of the first amino acid, translationinitiating methionine with a threonine in the ND5 polypeptide, and decreases ND5 mRNA levels and alters the processing of RNA precursors. In addition, this mutation is located in two nucleotides adjacent to the $3^{\prime}$ end of the tRNA ${ }^{\mathrm{Leu}(\mathrm{CUN})}$, and it is anticipated that the $\mathrm{T} 12338 \mathrm{C}$ mutation will lead to a reduction in tRNA ${ }^{\mathrm{Leu}(\mathrm{CUN})}$ levels, whereas the A12330G mutation disrupts the highly conserved base pairing (6T-67A) in the acceptor arm of tRNA ${ }^{\text {Leu(CUN) }}(45)$. Therefore, the combination of T12338C and A12330G mutations may have contributed to the high penetrance of EH in this Chinese family (43).

ND6 T14484C mutation. The T14484C mutation in the ND6 gene is one of the primary mutations associated with Leber's hereditary optic neuropathy (LHON) (46). In a recent study, a large Han Chinese family with maternally transmitted EH but not presenting any LHON phenotype, was found to be associated with the T14484C mutation (47). Analysis of the complete mtDNA sequence of the proband showed the absence of additional pathogenic mutations, apart from the T14484C mutation. Moreover, analysis of the mitochondrial function of lymphoblastoid cell lines established from the family members showed that mitochondrial respiration rate and membrane potential were significantly reduced when compared with the control cell lines. In addition, there was an increase in the levels of ROS and mitochondrial mass in the mutant cell lines. These data suggest that ND6 T14484C also plays an important role in the pathogenesis of $\mathrm{EH}$ and is also a pathogenic mutation associated with EH (47).

CyB G15059A mutation. The heteroplasmic G15059A mutation in $C y B$ gene was first described in a patient with mitochondrial myopathy (48). This substitution results in the replacement of a glycine at amino acid position 190 of $C y B$ with a stop codon leading to a truncated protein that misses 244 amino acids at the C-terminus of $C y B$ (49). Nikitin et al (50) examined the role of the $C y B$ G15059A mutation in patients with type 2 diabetes (T2D) with EH. In addition, the G15059A heteroplasmy level exceeding $39 \%$ was associated with an increased risk of $\mathrm{EH}$, indicating a direct pathogenic role for this mutation in $\mathrm{EH}(50)$.

50-bp deletion. The 50-bp deletion (m.298_347del50) in the mtDNA control region removes the conserved sequence block II (CSBII) and the replication primer location (51-53). This deletion, co-occurring with two novel mutations (ND1 C3519T and ND5 G13204A), accounted for the complex clinical traits, including hypertension, T2D and coronary artery disease (CAD) in an Indian family (54). Of note, two short homologous direct repeats of CCAAACCCC flanked the 50-bp deletion. The CSBII directs transcription termination and primer formation in mtDNA replication (55). Thus, it can be predicted that the 50-bp deletion may reduce the mtDNA copy number and decrease the levels of cellular energy. However, conflicting reports have shown that this deletion does not affect the mtDNA copy number (53); its functional role requires further elucidation in future studies. $t R N A^{\text {Ile }}$ A4295G mutation. The homoplasmic A4295G mutation in the tRNA ${ }^{\text {Ile }}$ gene was identified in a three generation Han Chinese family with maternally inherited EH (56). An A to $\mathrm{G}$ transition at nucleotide position 4295 was shown to be highly evolutionarily conserved, and was not present in the healthy controls (57). The A4295G mutation is localized at the $3^{\prime}$ end adjacent to the anticodon (position 37) of tRNA ${ }^{\text {Ile }}$ (45); nucleotide at position 37 is responsible for the stabilization of functional tRNA (58). Thus, it has been suggested that this mutation reduces the efficiency with which tRNA ${ }^{\text {Ile }}$ can be processed by 3'-tRNase, reducing the level of functional tRNA $^{\text {Ile }}$ (59). The functional characterization of the A4295G mutation shows that this mutation induces a significant decrease in complex III protein levels, leading to a decrease in the activity of this complex, which is reflected by the decline in mitochondrial respiration (60).

$t R N A^{\text {Ile }}$ A4263G mutation. The A4263G mutation changes the stop codon TAA of the NDI mRNA to an equivalent TAG stop codon. This mutation causes an $A$ to $G$ transition at the 5 ' end of the tRNA ${ }^{\text {Ile }}$ gene $(61,62)$. Cybrid cells derived from the proband carrying A4263G mutation show a reduction in tRNA $^{\text {Ile }}$ steady-state levels, as well as in the rate of mitochondrial protein translation. Increased ROS and the decreased efficiency of $5^{\prime}$ end processing of tRNA ${ }^{\text {Ile }}$ precursor indicated that this mutation caused mitochondrial dysfunction that was responsible for $\mathrm{EH}$ in this Han Chinese family (61).

tRNA ${ }^{\text {Ile }}$ T4291C mutation. The homoplasmic T4291C mutation in the tRNA ${ }^{\text {Ile }}$ gene has been associated with a cluster of metabolic defects, including hypertension, hypercholesterolemia and hypomagnesaemia in a large family (63). The T4291C mutation occurs immediately $5^{\prime}$ to the tRNA ${ }^{\text {Ile }}$ anticodon (position 33), and is conserved in every sequenced tRNA ${ }^{\text {Ile }}$ from bacteria to human mitochondria (64). Biochemical studies with anticodon stem-loop analogs of tRNAs have been performed and have indicated that the substitution of cytidine for uridine at this position markedly impairs ribosomal binding (65), providing evidence of the functional importance of this mutation.

tRNA ${ }^{\text {Met }}$ A4435G mutation. The presence of the A4435G mutation with chronic progressive external ophthalmoplegia (CPEO) was initially reported in the study by Jaksch et al (66). Later on, this mutation was found in patients with LHON (67), as well as in a Japanese subject with diabetes (68). In addition, the East Asian haplogroup G2a1-specific A4435G mutation (69) has also been associated with $\mathrm{EH}$ in two Chinese families (70,71). The homoplasmic A4435G mutation, which is located at immediately $3^{\prime}$ end to the anticodon of tRNA ${ }^{\mathrm{Met}}$ (nucleotide position 37 ), is extremely conserved from bacteria to human mitochondria (45). In fact, as shown in previous studies, the A4435G mutation causes $\sim 40-50 \%$ reduction in the steady-state level of tRNA ${ }^{\mathrm{Met}}$ and consequently results in the failure of mt-tRNA metabolism (67,70). Impaired mt-tRNA metabolism subsequently worsens the mitochondrial protein synthesis, decreases ATP production and increases ROS levels. Thus, mitochondrial dysfunction may contribute to the development of $\mathrm{EH}$ in these families carrying the A4435G point mutation $(37,63,72)$. 
Table I. Summary of cardiovascular diseases associated mt-tRNA mutations.

\begin{tabular}{|c|c|c|c|c|c|}
\hline Position & tRNA species & Allele & $\begin{array}{l}\text { Homoplasmy/ } \\
\text { heteroplasmy }\end{array}$ & Clinical features & Refs. \\
\hline 29 & $\mathrm{tRNA}^{\mathrm{Val}}$ & $\mathrm{C} 1628 \mathrm{~T}$ & Homoplasmy & Cardiomyopathy & $(80)$ \\
\hline 14 & tRNA ${ }^{\mathrm{Leu}(U U R)}$ & A $3243 G$ & Heteroplasmy & Cardiomyopathy & $(81)$ \\
\hline 29 & tRNA $^{\mathrm{Leu}(\mathrm{UUR})}$ & A3260G & Heteroplasmy & Myopathy, cardiomyopathy, MELAS & $(82-84)$ \\
\hline 72 & tRNA $^{\mathrm{Leu}(\mathrm{UUR})}$ & $\mathrm{C} 3303 \mathrm{~T}$ & Homoplasmy & Cardiomyopathy, myopathy, HCM & $(85-87)$ \\
\hline 1 & $\mathrm{tRNA}^{\mathrm{Ile}}$ & A4263G & Homoplasmy & Hypertension & $(61)$ \\
\hline 7 & $\mathrm{tRNA}^{\mathrm{Ile}}$ & A4269G & Homoplasmy & Cardiomyopathy & $(88)$ \\
\hline 15 & tRNA ${ }^{\text {Ile }}$ & $\mathrm{T} 4277 \mathrm{C}$ & Homoplasmy & Cardiomyopathy & (89) \\
\hline 33 & $\mathrm{tRNA}^{\mathrm{Ile}}$ & $\mathrm{T} 4291 \mathrm{C}$ & Homoplasmy & $\begin{array}{l}\text { Hypertension, hypercholesterolemia, } \\
\text { hypomagnesaemia }\end{array}$ & (63) \\
\hline 37 & $\mathrm{tRNA}^{\mathrm{Ile}}$ & A4295G & Homoplasmy & HCM, hypertension & $(56,57)$ \\
\hline 42 & $\mathrm{tRNA}^{\mathrm{Ile}}$ & A4300G & Homoplasmy & $\mathrm{HCM}$ & $(90)$ \\
\hline 37 & $\mathrm{tRNA}^{\mathrm{Met}}$ & A4435G & Homoplasmy & LHON, CPEO, hypertension & $(66-68,70,71)$ \\
\hline 1 & $\mathrm{tRNA}^{\mathrm{Gln}}$ and tRNA ${ }^{\mathrm{Met}}$ & A4401G & Homoplasmy & LVH, hypertension & $(73,74)$ \\
\hline 49 & $\mathrm{tRNA}^{\mathrm{Gln}}$ & $\mathrm{T} 4353 \mathrm{C}$ & Homoplasmy & Hypertension & (76) \\
\hline 58 & $\mathrm{tRNA}^{\mathrm{Ala}}$ & A5600T & Heteroplasmy & $\mathrm{DCM}$ & $(91)$ \\
\hline 54 & tRNA $^{\text {Lys }}$ & A8348G & Heteroplasmy & Cardiomyopathy & $(92)$ \\
\hline 7 & tRNA $^{\text {Gly }}$ & T9997C & Heteroplasmy & $\mathrm{HCM}$ & (93) \\
\hline 59 & $\mathrm{tRNA}^{\mathrm{His}}$ & G12192A & Homoplasmy & Cardiomyopathy & (94) \\
\hline 67 & $\mathrm{tRNA}^{\mathrm{Leu}(\mathrm{CUN})}$ & A12330G & Homoplasmy & Hypertension & (43) \\
\hline 37 & tRNA $^{\text {Glu }}$ & $\mathrm{T} 14709 \mathrm{C}$ & Homoplasmy & Cardiomyopathy & $(95)$ \\
\hline 2 & tRNA $^{\text {Thr }}$ & $\mathrm{T} 15889 \mathrm{C}$ & Heteroplasmy & DCM & $(91)$ \\
\hline 16 & tRNA ${ }^{\mathrm{Thr}}$ & A15902G & Heteroplasmy & DCM & $(91)$ \\
\hline 38 & tRNA ${ }^{\text {Thr }}$ & $\mathrm{T} 15924 \mathrm{C}$ & Homoplasmy & DCM & (96) \\
\hline 51 & $\mathrm{tRNA}^{\mathrm{Thr}}$ & A15935G & Heteroplasmy & DCM & $(91)$ \\
\hline
\end{tabular}

MELAS, mitochondrial encephalomyopathy, lactic acidosis and stroke-like episodes; HCM, hypertrophic cardiomyopathy; LVH, left ventricular hypertrophy; LHON, Leber's hereditary optic neuropathy; CPEO, chronic progressive external ophthalmoplegia; DCM, dilated cardiomyopathy.

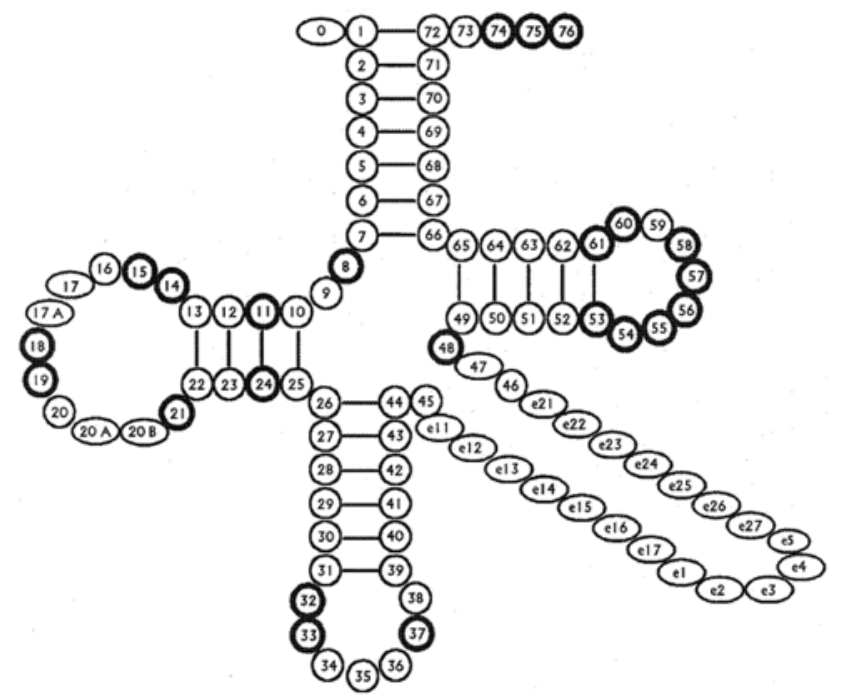

Figure 2. Cloverleaf structure of mt-tRNA with standard nucleotide numbering. The nucleotides in the variable stem have the prefix ' $e$ ' and are located between positions 45 and 46, obeying the base-pairing rules. The nucleotides in the 54-strand and 34-strand are numbered by e11, e12, e13; the second digit identifies the base-pair.
A4401G mutation in $t R N A^{\text {Met }}$ and $t R N A^{\mathrm{Gln}}$. The homoplasmic A $4401 \mathrm{G}$ mutation was originally described in a three generation Chinese family with left ventricular hypertrophy (LVH) (73). This mutation was also present in a five generation Chinese pedigree with EH (74). The A4401G mutation is localized at the junction of tRNA ${ }^{\mathrm{Met}}$ at the $\mathrm{H}$-strand and tRNA ${ }^{\mathrm{Gln}}$ at the L-strand (75). Thus, it is anticipated that this mutation may lead to defective tRNA ${ }^{\text {Met }} 5$ ' end processing in the H-strand transcripts and reduce the efficiency of tRNA ${ }^{\text {Gln }}$ precursor 5 ' end cleavage in the L-strand transcripts. Functional characterization of cell lines derived from the proband carrying the A4401G mutation shows virtually $\sim 30 \%$ reduction in the levels of tRNA ${ }^{\text {Ile }}$ and tRNA ${ }^{\text {Gln }}$ (74). In addition, the mutant cell lines present a significant decrease in the oxygen consumption rate (73). These findings indicate that the A4401G mutation is involved in the pathogenesis of EH in Han Chinese families.

T4353C mutation in $t R N A^{\mathrm{Gln}}$. The $\mathrm{T} 4353 \mathrm{C}$ mutation, in conjunction with the tRNATrp C593T mutation, has been shown to account for the high penetrance of EH in a Han Chinese family (76). Clinical evaluation of this family showed a typical 
maternally transmitted pattern. Analysis of the complete mtDNA sequence identified the homoplasmic T4353C mutation. This mutation alters a conservative base-pairing (49A-65U) on the $\mathrm{T}$ arm of tRNA ${ }^{\mathrm{Gln}}$, thereby affecting tRNA metabolism (45). Moreover, the T4353C mutation reduces the steady-state level of tRNA ${ }^{\text {Gln }}$, mutant tRNA ${ }^{\text {Gln }}$ and tRNA ${ }^{\text {Phe }}$ may be metabolically less stable and more subject to degradation. The cybrid cell lines carrying the T4353C mutation present mitochondrial protein synthesis defects. As a result, this mutation causes the mitochondrial dysfunction responsible for $\mathrm{EH}$.

\section{Molecular mechanisms behind mtDNA mutations associated with EH}

In previous studies, we noticed that several hypertensionassociated mitochondrial pathogenic mutations were located in tRNA genes. Mt-tRNA mutations have structural and functional effects, including destabilization of the tRNA tertiary structure, altered processing of RNA precursors, loss of nucleotide modification and deficient aminoacylation (Fig. 2 and Table I). In particular, these pathogenic mutations may lead to deficiencies in tRNA $3^{\prime}$ end metabolism including $3^{\prime}$ end cleavage, CCA addition, aminoacylation or impairment of critical subunits of respiratory chain functions. Failures in mt-tRNA metabolism subsequently lead to the impairment of mitochondrial protein (77-79). However, mutations in protein coding genes may have the potential to affect OXPHOS and in turn cellular death, resulting in a failure in mitochondrial protein synthesis. The increased bioavailability of ROS results in oxidative stress, which leads to cardiovascular and renal damage, thus, contributing to EH.

\section{Conclusion}

$\mathrm{EH}$ is a multifactorial syndrome that is characterized by abnormal energy metabolism and high BP. Recent studies have identified the mitochondria as the target and origin of major pathogenic pathways which lead to the progression of hypertension (97-99). Although existing therapies have been beneficial, there is a clear need for new approaches to treatment. Pharmacological targeting of the cellular stresses underlying mitochondrial dysfunction is showing promise. In addition, screening for mtDNA mutations for the clinical expression of hypertension may provide further insight into the understanding of the pathophysiology for maternally inherited hypertension.

\section{Acknowledgements}

This study was supported by grants from the Ministry of Public Health of Zhejiang Province (2013KYA158), Nanjing Medical University (no. 2010NJMU011), Hangzhou Bureau of Science and Technology (no. 20120533Q03) and the Specialized Research Fund for the Doctoral Program of Higher Education (no. 20124323120004).

\section{References}

1. El Shamieh S, Herbeth B, Azimi-Nezhad M, et al: Human formyl peptide receptor $1 \mathrm{C} 32 \mathrm{~T} \mathrm{SNP}$ interacts with age and is associated with blood pressure levels. Clin Chim Acta 413: 34-38, 2012.
2. Kearney PM, Whelton M, Reynolds K, et al: Global burden of hypertension: analysis of worldwide data. Lancet 365: 217-223, 2005.

3. Messerli FH, Williams B and Ritz E: Essential hypertension. Lancet 370: 591-560, 2007.

4. Kunes J and Zicha J: Developmental windows and environment as important factors in the expression of genetic information: a cardiovascular physiologist's view. Clin Sci 111: 295-305, 2006.

5. Timberlake DS, O'Connor DT and Parmer RJ: Molecular genetics of essential hypertension: recent results and emerging strategies. Curr Opin Nephrol Hypertens 10: 71-79, 2001.

6. Fan JB, Chen X, Halushka MK, et al: Parallel genotyping of human SNPs using generic high-density oligonucleotide tag arrays. Genome Res 10: 853-860, 2000.

7. Oliphant A, Barker DL, Stuelpnagel JR and Chee MS: BeadArray technology: enabling an accurate, cost-effective approach to high-throughput genotyping. Biotechniques 56 (Suppl 56-58): 60-61, 2002.

8. Levy D, Ehret GB, Rice K, et al: Genome-wide association study of blood pressure and hypertension. Nat Genet 41: 677-687, 2009.

9. Tobin MD, Tomaszewski M, Braund PS, et al: Common variants in genes underlying monogenic hypertension and hypotension and blood pressure in the general population. Hypertension 51: 1658-1664, 2008

10. Padmanabhan S, Melander O, Johnson T, et al: Genome-wide association study of blood pressure extremes identifies variant near UMOD associated with hypertension. PLoS Genet 6: e1001177, 2010.

11. Schon EA: Mitochondria. In: Encyclopedia of Human Biology. Dulbecco R (ed). Vol 5. 2nd edition. Academic Press, London, pp713-724, 1997.

12. Wallace DC: Mitochondrial DNA mutations in disease and aging. Environ Mol Mutagen 51: 440-450, 2010.

13. Garcia-Rodriguez LJ: Appendix 1. Basic properties of mitochondria. Methods Cell Biol 80: 809-812, 2007.

14. DiMauro S and Schon EA: Mitochondrial DNA mutations in human disease. Am J Med Genet 106: 18-26, 2001.

15. Cadenas E and Davies KJ: Mitochondrial free radical generation, oxidative stress, and aging. Free Radic Biol Med 29: 222-230, 2000.

16. Schon EA, DiMauro S and Hirano M: Human mitochondrial DNA: roles of inherited and somatic mutations. Nat Rev Genet 13: 878-890, 2012.

17. McBride HM, Neuspiel M and Wasiak S: Mitochondria: more than just a powerhouse. Curr Biol 16: R551-R560, 2006.

18. Choksi KB, Boylston WH, Rabek JP, et al: Oxidatively damaged proteins of heart mitochondrial electron transport complexes. Biochim Biophys Acta 1688: 95-101, 2004.

19. Murphy MP: Induction of mitochondrial ROS production by electrophilic lipids: a new pathway of redox signaling? Am J Physiol Heart Circ Physiol 290: H1754-H1755, 2006.

20. Abou-Sleiman PM, Muqit MM and Wood NW: Expanding insights of mitochondrial dysfunction in Parkinson's disease. Nat Rev Neurosci 7: 207-219, 2006.

21. Li P, Nijhawan D and Wang X: Mitochondrial activation of apoptosis. Cell 116 (Suppl 2): S57-S59, 2004.

22. Wu L and Juurlink BH: Increased methylglyoxal and oxidative stress in hypertensive rat vascular smooth muscle cells. Hypertension 39: 809-814, 2002.

23. Lerman LO, Nath KA, Rodriguez-Porcel M, et al: Increased oxidative stress in experimental renovascular hypertension. Hypertension 37: 541-546, 2001.

24. Trolliet MR, Rudd MA and Loscalzo J: Oxidative stress and renal dysfunction in salt-sensitive hypertension. Kidney Blood Press Res 24: 116-123, 2001.

25. Romero JC and Reckelhoff JF: State-of-the-Art lecture. Role of angiotensin and oxidative stress in essential hypertension. Hypertension 34: 943-949, 1999.

26. Hamilton CA, Berg G, McIntyre M, et al: Effects of nitric oxide and superoxide on relaxation in human artery and vein. Atherosclerosis 133: 77-86, 1997.

27. Paravicini TM and Touyz RM: Redox signaling in hypertension. Cardiovasc Res 71: 247-258, 2006

28. Prezant TR, Agapian JV, Bohlman MC, et al: Mitochondrial ribosomal RNA mutation associated with both antibiotic-induced and non-syndromic deafness. Nat Genet 4: 289-294, 1993.

29. Estivill X, Govea N, Barceló E, et al: Familial progressive sensorineural deafness is mainly due to the mtDNA A $1555 \mathrm{G}$ mutation and is enhanced by treatment of aminoglycosides. Am J Hum Genet 62: 27-35, 1998 . 
30. Guan MX: Molecular pathogenetic mechanism of maternally inherited deafness. Ann NY Acad Sci 1011: 259-271, 2004.

31. Van Camp G and Smith RJ: Maternally inherited hearing impairment. Clin Genet 57: 409-414, 2000.

32. Chen H, Zheng J, Xue L, et al: The $12 \mathrm{~S}$ rRNA A1555G mutation in the mitochondrial haplogroup D5a is responsible for maternally inherited hypertension and hearing loss in two Chinese pedigrees. Eur J Hum Genet 20: 607-612, 2012.

33. Hamasaki K and Rando RR: Specific binding of aminoglycosides to a human rRNA construct based on a DNA polymorphism which causes aminoglycoside-induced deafness. Biochemistry 36 12323-12328, 1997.

34. Cotney J, McKay SE and Shadel GS: Elucidation of separate, but collaborative functions of the rRNA methyltransferaserelated human mitochondrial transcription factors B1 and B2 in mitochondrial biogenesis reveals new insight into maternally inherited deafness. Hum Mol Genet 18: 2670-2682, 2009.

35. Hobbie SN, Bruell CM, Akshay S, et al: Mitochondrial deafness alleles confer misreading of the genetic code. Proc Natl Acad Sci USA 105: 3244-3249, 2008

36. Guan MX, Fischel-Ghodsian N and Attardi G: Nuclear background determines biochemical phenotype in the deafnessassociated mitochondrial $12 \mathrm{~S}$ rRNA mutation. Hum Mol Genet 10: 573-580, 2001

37. Bernal-Mizrachi C, Gates AC, Weng S, et al: Vascular respiratory uncoupling increases blood pressure and atherosclerosis. Nature 435: 502-506, 2005.

38. Li X, Fischel-Ghodsian N, Schwartz F, et al: Biochemical characterization of the mitochondrial tRNA ${ }^{\text {Ser(UCN) }}$ T7511C mutation associated with nonsyndromic deafness. Nucleic Acids Res 32: 867-877, 2004

39. Li R, Ishikawa K, Deng JH, et al: Maternally inherited nonsyndromic hearing loss is associated with the T7511C mutation in the mitochondrial tRNA ${ }^{\text {SerUCN }}$ gene in a Japanese family. Biochem Biophys Res Commun 328: 32-37, 2005.

40. Liu Y, Li Z, Yang L, et al: The mitochondrial ND1 T3308C mutation in a Chinese family with the secondary hypertension. Biochem Biophys Res Commun 368: 18-22, 2008.

41. Anderson S, Bankier AT, Barrell BG, et al: Sequence and organization of the human mitochondrial genome. Nature 290 457-465, 1981

42. Guan MX, Enriquez JA, Fischel-Ghodsian N, et al: The deafnessassociated mitochondrial DNA mutation at position 7445, which affects tRNA ${ }^{\mathrm{Ser}(\mathrm{UCN})}$ precursor processing, has long-range effects on NADH dehydrogenase subunit ND6 gene expression. Mol Cell Biol 18: 5868-5879, 1998

43. Teng L, Zheng J, Leng J and Ding Y: Clinical and molecular characterization of a Han Chinese family with high penetrance of essential hypertension. Mitochondrial DNA 23: 461-465, 2012.

44. Liu Z, Song Y, Gu S, et al: Mitochondrial ND5 12338T>C variant is associated with maternally inherited hypertrophic cardiomyopathy in a Chinese pedigree. Gene 506: 339-343, 2012

45. Florentz C, Sohm B, Tryoen-Tóth P, et al: Human mitochondrial tRNAs in health and disease. Cell Mol Life Sci 60: 1356-1375, 2003.

46. Yu-Wai-Man P, Griffiths PG, Hudson G and Chinnery PF: Inherited mitochondrial optic neuropathies. J Med Genet 46 145-158, 2009.

47. Guo H, Zhuang XY, Zhang AM, et al: Presence of mutation m.14484T $>C$ in a Chinese family with maternally inherited essential hypertension but no expression of LHON. Biochim Biophys Acta 1822: 1535-1543, 2012.

48. Andreu AL, Hanna MG, Reichmann H, et al: Exercise intolerance due to mutations in the cytochrome $b$ gene of mitochondrial DNA. N Engl J Med 341: 1037-1044, 1999.

49. Andreu AL, Bruno C, Dunne TC, et al: A nonsense mutation (G15059A) in the cytochrome b gene in a patient with exercise intolerance and myoglobinuria. Ann Neurol 45: 127-130, 1999.

50. Nikitin AG, Lavrikova EY and Chistiakov DA: The heteroplasmic $15059 \mathrm{G}>\mathrm{A}$ mutation in the mitochondrial cytochrome $\mathrm{b}$ gene and essential hypertension in type 2 diabetes. Diabetes Metab Syndr 6: 150-156, 2012.

51. Chang DD and Clayton DA: Priming of human mitochondrial DNA replication occurs at the light-strand promoter. Proc Natl Acad Sci USA 82: 351-355, 1985.

52. Kang D, Miyako K, Kai Y, et al: In vivo determination of replication origins of human mitochondrial DNA by ligationmediated polymerase chain reaction. J Biol Chem 272: 15275-15279, 1997.
53. Bi R, Zhang AM, Zhang W, et al: The acquisition of an inheritable 50-bp deletion in the human mtDNA control region does not affect the mtDNA copy number in peripheral blood cells Hum Mutat 31: 538-543, 2010.

54. Elango S, Govindaraj P, Vishwanadha VP, et al: Analysis of mitochondrial genome revealed a rare 50 bp deletion and substitutions in a family with hypertension. Mitochondrion 11: 878-885, 2011.

55. Pham XH, Farge G, Shi Y, et al: Conserved sequence box II directs transcription termination and primer formation in mitochondria. J Biol Chem 281: 24647-24652, 2006.

56. Li Z, Liu Y, Yang L, et al: Maternally inherited hypertension is associated with the mitochondrial tRNA(Ile) A4295G mutation in a Chinese family. Biochem Biophys Res Commun 367: 906-911, 2008

57. Merante F, Myint T, Tein I, et al: An additional mitochondrial tRNA(Ile) point mutation (A-to-G at nucleotide 4295) causing hypertrophic cardiomyopathy. Hum Mutat 8: 216-222, 1996.

58. Suzuki T, Nagao A and Suzuki T: Human mitochondrial tRNAs: biogenesis, function, structural aspects, and diseases. Annu Rev Genet 45: 299-329, 2011.

59. Levinger L, Giegé R and Florentz C: Pathology-related substitutions in human mitochondrial tRNA(Ile) reduce precursor 3' end processing efficiency in vitro. Nucleic Acids Res 31: 1904-1912, 2003.

60. Gutiérrez Cortés N, Pertuiset C, Dumon E, et al: Novel mitochondrial DNA mutations responsible for maternally inherited nonsyndromic hearing loss. Hum Mutat 33: 681-689, 2012.

61. Wang S, Li R, Fettermann A, et al: Maternally inherited essential hypertension is associated with the novel $4263 \mathrm{~A}>\mathrm{G}$ mutation in the mitochondrial tRNA ${ }^{\text {Ile }}$ gene in a large Han Chinese family. Circ Res 108: 862-870, 2011.

62. Zhu HY, Wang SW, Liu L, et al: Genetic variants in mitochondrial tRNA genes are associated with essential hypertension in a Chinese Han population. Clin Chim Acta 410: 64-69, 2009.

63. Wilson FH, Hariri A, Farhi A, et al: A cluster of metabolic defects caused by mutation in a mitochondrial tRNA. Science 306: 1190-1194, 2004

64. Sprinzl M, Steegborn C, Hübel F and Steinberg S: Compilation of tRNA sequences and sequences of tRNA genes. Nucleic Acids Res 24: 68-72, 1996.

65. Ashraf SS, Sochacka E, Cain R, et al: Single atom modification $(\mathrm{O} \rightarrow \mathrm{S})$ of tRNA confers ribosome binding. RNA 5: 188-194, 1999.

66. Jaksch M, Kleinle S, Scharfe C, et al: Frequency of mitochondrial transfer RNA mutations and deletions in 225 patients presenting with respiratory chain deficiencies. J Med Genet 38: 665-673, 2001

67. Qu J, Li R, Zhou X, et al: The novel A4435G mutation in the mitochondrial tRNA ${ }^{\text {Met }}$ may modulate the phenotypic expression of the LHON-associated ND4 G11778A mutation. Invest Ophthalmol Vis Sci 47: 475-483, 2006.

68. Guo LJ, Oshida Y, Fuku N, et al: Mitochondrial genome polymorphisms associated with type-2 diabetes or obesity. Mitochondrion 5: 15-33, 2005.

69. Kong QP, Bandelt HJ, Sun C, et al: Updating the East Asian mtDNA phylogeny: a prerequisite for the identification of pathogenic mutations. Hum Mol Genet 15: 2076-2086, 2006.

70. Liu Y,Li R, Li Z, et al: Mitochondrial transfer RNAMet 4435A>G mutation is associated with maternally inherited hypertension in a Chinese pedigree. Hypertension 53: 1083-1090, 2009.

71. Lu Z, Chen H, Meng Y, et al: The tRNA ${ }^{\text {Met }} 4435 \mathrm{~A}>\mathrm{G}$ mutation in the mitochondrial haplogroup G2a1 is responsible for maternally inherited hypertension in a Chinese pedigree. Eur J Hum Genet 19: 1181-1186, 2011

72. Postnov YV, Orlov SN, Budnikov YY, et al: Mitochondrial energy conversion disturbance with decrease in ATP production as a source of systemic arterial hypertension. Pathophysiology 14 : 195-204, 2007.

73. Zhu HY, Wang SW, Liu L, et al: A mitochondrial mutation A4401G is involved in the pathogenesis of left ventricular hypertrophy in Chinese hypertensives. Eur J Hum Genet 17: 172-178, 2009.

74. Li R, Liu Y, Li Z, et al: Failures in mitochondrial tRNA ${ }^{\mathrm{Met}}$ and tRNA $^{\text {Gln }}$ metabolism caused by the novel $4401 \mathrm{~A}>\mathrm{G}$ mutation are involved in essential hypertension in a Han Chinese Family. Hypertension 54: 329-337, 2009.

75. Ojala D, Montoya J and Attardi G: tRNA punctuation model of RNA processing in human mitochondria. Nature 290: 470-474, 1981.

76. Qiu Q, Li R, Jiang P, et al: Mitochondrial tRNA mutations are associated with maternally inherited hypertension in two Han Chinese pedigrees. Hum Mutat 33: 1285-1293, 2012. 
77. Levinger L, Mörl M and Florentz C: Mitochondrial tRNA 3 end metabolism and human disease. Nucleic Acids Res 32: 5430-5441, 2004.

78. Kelley SO, Steinberg SV and Schimmel P: Functional defects of pathogenic human mitochondrial tRNAs related to structural fragility. Nat Struct Biol 7: 862-865, 2000.

79. Kelley SO, Steinberg SV and Schimmel P: Fragile T-stem in disease-associated human mitochondrial tRNA sensitizes structure to local and distant mutations. J Biol Chem 276: 10607-10611, 2001.

80. Arredondo JJ, Gallardo ME, García-Pavía P, et al: Mitochondrial tRNA valine as a recurrent target for mutations involved in mitochondrial cardiomyopathies. Mitochondrion 12: 357-362, 2012.

81. Vilarinho L, Santorelli FM, Rosas MJ, et al: The mitochondria A3243G mutation presenting as severe cardiomyopathy. J Med Genet 34: 607-609, 1997.

82. Zeviani M, Gellera C, Antozzi C, et al: Maternally inherited myopathy and cardiomyopathy: association with mutation in mitochondrial DNA tRNA(Leu)(UUR). Lancet 338: 143-147, 1991.

83. Sweeney MG, Brockington M, Weston MJ, et al: Mitochondrial DNA transfer RNA mutation Leu(UUR)A $\rightarrow$ G 3260: a second family with myopathy and cardiomyopathy. Q J Med 86: 435-438, 1993.

84. Nishino I, Komatsu M, Kodama S, et al: The 3260 mutation in mitochondrial DNA can cause mitochondrial myopathy, encephalopathy, lactic acidosis, and strokelike episodes (MELAS) Muscle Nerve 19: 1603-1604, 1996.

85. Goldstein JD, Shanske S, Bruno C and Perszyk AA: Maternally inherited mitochondrial cardiomyopathy associated with a C-to-T transition at nucleotide 3303 of mitochondrial DNA in the tRNA(Leu(UUR)) gene. Pediatr Dev Pathol 2: 78-85, 1999.

86. Silvestri G, Santorelli FM, Shanske S, et al: A new mtDNA mutation in the tRNA(Leu(UUR)) gene associated with maternally inherited cardiomyopathy. Hum Mutat 3: 37-43, 1994

87. Palecek T, Tesarova M, Kuchynka P, et al: Hypertrophic cardiomyopathy due to the mitochondrial DNA mutation m.3303C $>\mathrm{T}$ diagnosed in an adult male. Int Heart J 53: 383-387, 2012.

88. Taniike M, Fukushima H, Yanagihara I, et al: Mitochondrial tRNA(Ile) mutation in fatal cardiomyopathy. Biochem Biophys Res Commun 186: 47-53, 1992.
89. Giordano C, Perli E, Orlandi M,et al: Cardiomyopathies due to homoplasmic mitochondrial tRNA mutations: morphologic and molecular features. Hum Pathol 44: 1262-1270, 2013.

90. Taylor RW, Giordano C, Davidson MM, et al: A homoplasmic mitochondrial transfer ribonucleic acid mutation as a cause of maternally inherited hypertrophic cardiomyopathy. J Am Coll Cardiol 41: 1786-1796, 2003.

91. Arbustini E, Diegoli M, Fasani R, et al: Mitochondrial DNA mutations and mitochondrial abnormalities in dilated cardiomyopathy. Am J Pathol 153: 1501-1510, 1998.

92. Terasaki F, Tanaka M, Kawamura K, et al: A case of cardiomyopathy showing progression from the hypertrophic to the dilated form: association of Mt8348A $\rightarrow \mathrm{G}$ mutation in the mitochondrial tRNA(Lys) gene with severe ultrastructural alterations of mitochondria in cardiomyocytes. Jpn Circ J 65: 691-694, 2001.

93. Merante F, Tein I, Benson L and Robinson BH: Maternally inherited hypertrophic cardiomyopathy due to a novel T-to-C transition at nucleotide 9997 in the mitochondrial tRNA(glycine) gene. Am J Hum Genet 55: 437-446, 1994.

94. Shin WS, Tanaka M, Suzuki J, et al: A novel homoplasmic mutation in mtDNA with a single evolutionary origin as a risk factor for cardiomyopathy. Am J Hum Genet 67: 1617-1620, 2000.

95. Van Hove JL, Freehauf C, Miyamoto S, et al: Infantile cardiomyopathy caused by the T14709C mutation in the mitochondrial tRNA glutamic acid gene. Eur J Pediatr 167: 771-776, 2008.

96. Ruppert V, Nolte D, Aschenbrenner T, et al: Novel point mutations in the mitochondrial DNA detected in patients with dilated cardiomyopathy by screening the whole mitochondrial genome. Biochem Biophys Res Commun 318: 535-543, 2004.

97. Dikalov S: Cross talk between mitochondria and NADPH oxidases. Free Radic Biol Med 51: 1289-1301, 2011.

98. Leone TC and Kelly DP: Transcriptional control of cardiac fuel metabolism and mitochondrial function. Cold Spring Harb Symp Quant Biol 76: 175-182, 2011.

99. Cottrill KA and Chan SY: Metabolic dysfunction in pulmonary hypertension: the expanding relevance of the Warburg effect. Eur J Clin Invest 43: 855-865, 2013. 